A - Research concept and design

B - Collection and/or assembly of data

$\mathrm{C}$ - Data analysis and interpretation

D - Writing the article

E - Critical revision of the article

F - Final approval of article

\section{Assessment of online physiotherapy consultation for children - parents' opinions}

\author{
Anna Kloze ${ }^{* A, D-F}$ (iD), Zuzanna Wojtal ${ }^{\mathrm{B}-\mathrm{C}}$ (iD) \\ Faculty of Rehabilitation, Józef Piłsudski University of Physical Education \\ in Warsaw, Poland
}

*Correspondence: Anna Kloze; Józef Piłsudski University of Physical Education, Faculty of Rehabilitation, Poland; email: anna.kloze@op.pl

\begin{abstract}
Introduction: The COVID-19 epidemic has forced a change in the way contact with the physiotherapist is organised. This sitaution has created a risk for infants exposed to worsening disorders resulting from rehabilitation measures not being implemented or being interrupted. The online physiotherapy consultations, which were practised thus far, have become widespread.

Material and methods: An online diagnostic survey was conducted among 151 parents of infants who had received an online physiotherapy consultation during the pandemic period. The survey comprised 25 questions. These questions concerned the impact of online consultation on increasing parents' sense of competence, the possibility of replacing in-clinic consultation with online consultation, and identifying the benefits and limitations of conducting this form of support. Relationships between variables were tested using the chi-square test with a significance level of $\mathrm{p}=0.05$.

Results: The questionnaire data showed that the reasons for using online consultation were: muscle tone disorders, positioning asymmetry, motor development delay, assessing the child's development and learning how to properly care for the infant. The benefits of an online visit included saving time by not travelling to the physiotherapist and the opportunity to consult a specialist who would otherwise be impossible to meet due to distance. The respondents indicated the lack of physiotherapists in their place of residence. The sense of security for the child in a familiar environment was emphasised, while challenges were posed by the lack of direct contact with the physiotherapist and the organisational and equipment requirements of the visit.

Conclusions: Online consultations restore the possibility of continuing therapy and early diagnosis, as well as increasing parents' sense of competence. Although online consultation cannot replace in-person consultation, it can be a good complement or an alternative in some therapeutic situations.
\end{abstract}

Keywords: on-line, consultation, child development

\section{Introduction}

The outbreak of the global COVID-19 epidemic caused by the SARS-CoV-2 coronavirus in early 2020 necessitated a radical change in the way healthcare is organised, including the forms of contact with physiotherapists. Almost overnight, patients were deprived of rehabilitation services. Such a state of affairs created

This is an Open Access journal, all articles are distributed under the terms of the Creative Commons Attribution-NonCommercial-ShareAlike 4.0 International (CC BY-NC-SA 4.0). License (http://creativecommons. org/licenses/by-nc-sa/4.0/). 
a grave risk for infants, who are particularly vulnerable to significant and irreversible worsening of disorders as a result of rehabilitation measures being interrupted or not implemented. Consequently, parents began to seek help on the Internet, and this is how video consultation in paediatric physiotherapy, a form of telemedicine that had previously been practised very rarely, became widespread in Poland. As the aim of infant physiotherapy is to increase the child's development capability, eliminate disorders and prevent secondary consequences of developmental dysfunctions, diagnosing infants and introducing support activities should be undertaken as early as possible. This is of such importance because it is in the first period of life that the most dynamic development is observed, which is connected with the exceptionally high plasticity of the brain at this time [1-4]. An important aspect that impacts on the effectiveness of the improvement process is the attitude of parents and carers. The parents' sense of their own competence and awareness of the importance of early intervention and knowledge of the principles of correct child care are important factors in determining the success of therapy. Parents of the youngest children have the most enthusiasm, strength and hope, which is also connected with their being more involved in the child's therapy and cooperating more closely with specialists [5]. Physiotherapists have offered a service previously deemed unpopular by parents - video consultations involving parents, infants and physiotherapists.

The aim of this study was to evaluate how parents perceive the use of an online form of paediatric physiotherapy consultations.

The authors formulated the following research questions:

1. Does online consultation increase parents' sense of competence in dealing with their child appropriately?

2. In the opinion of the parents of infants and young children, what are the advantages of online consultation?

3. What do parents of infants and young children think are the main difficulties and limitations of online consultation?

4. Is the online consultation likely to replace face-toface consultation in the future?

\section{Material and methods}

The study group consisted of the parents of children aged from birth to four years old who used a video consultation with a physiotherapist for their child during the Covid-19 pandemic. The study sample was 151 parents, of whom $99 \%$ were the mothers of children and $1 \%$ were fathers.
The study used the diagnostic survey method. The survey was based on a tool developed by the paper's authors, which concerned the merits of using online video consultations with a physiotherapist during a pandemic. The questions referred to the following: demographic and social affiliation of the respondents, information on previous visits to a physiotherapist, if any, and the reasons why the respondents had decided to use this form of assistance. Questions were asked about the consultation process, the respondents' feelings about it, its effects and whether it met the parents' expectations. The survey form is available in supplementary materials (supplement 1).

The survey was conducted between 23.04.2020 and 06.05.2020. It was published on social media on the profiles of 5 physiotherapists who had conducted video consultations in the last 3 months since the start of the study. The responses were categorised and the relationships between the responses to individual questions were analysed. For this purpose, a summary database was created in Microsoft Excel 2007 based on the data from the questionnaires. The relationships between the variables were tested using the chi-square test with a significance level of $\mathrm{p}=0.05$.

\section{Results}

The questionnaire data showed that the vast majority of respondents, i.e. 136 people, live in Poland; however, there were also respondents living abroad (table 1). Respondents who had received in-clinic physiotherapy before the pandemic (113 people) were asked about the reasons for their previous consultations. The most frequently mentioned reasons were: muscle tone disorders, positioning asymmetry, motor development delay, the desire to assess the child's development and to learn proper infant care. 12 respondents admitted that previous physiotherapy consultations were due to a disease having been diagnosed in the child that impeded normal motor development.

80 of the 113 respondents said that the online consultation was carried out by the same physiotherapist who had previously conducted the child's therapy. Only 33 respondents decided to use a different physiotherapist; of these respondents, 28 reported that the therapist they had previously worked with did not conduct online video consultations and five respondents deliberately chose a different therapist to obtain a second opinion. 15 respondents admitted that they had used the online consultation because it provided an opportunity to contact a particular physiotherapist.

All 151 respondents were asked why they had chosen online consultations. Among the respondents who 
Tab 1. Characteristics of study participants

\begin{tabular}{|c|c|c|c|c|}
\hline \multirow{2}{*}{$\begin{array}{l}\text { Characteristic } \\
\text { Country of residence }\end{array}$} & \multicolumn{4}{|c|}{ Quantitative parameter } \\
\hline & $\begin{array}{l}\text { Poland } \\
136 \text { individuals }\end{array}$ & $\begin{array}{l}\text { Abroad } \\
15 \text { individuals }\end{array}$ & & \\
\hline Place of residence & $\begin{array}{l}\text { Up to } 50,000 \\
\text { inhabitants } \\
62 \text { individuals }\end{array}$ & $\begin{array}{l}\text { From } 50,000 \text { to } \\
150,000 \text { inhabitants } \\
16 \text { individuals }\end{array}$ & $\begin{array}{l}\text { From } 150,000 \text { to } \\
500,000 \text { inhabitants } \\
18 \text { individuals }\end{array}$ & $\begin{array}{l}\text { Over } 500,000 \\
\text { inhabitants } \\
55 \text { individuals }\end{array}$ \\
\hline Age of child & $\begin{array}{l}\text { Up to } 6 \text { months } \\
76 \text { children }\end{array}$ & $\begin{array}{l}\text { From } 7 \text { to } 12 \\
\text { months } \\
52 \text { children } \\
\end{array}$ & $\begin{array}{l}\text { Over } 12 \text { months } \\
23 \text { children }\end{array}$ & \\
\hline $\begin{array}{l}\text { Used in-clinic } \\
\text { physiotherapy } \\
\text { consultation prior to } \\
\text { online consultation }\end{array}$ & $\begin{array}{l}\text { Yes } \\
113 \text { individuals }\end{array}$ & $\begin{array}{l}\text { No } \\
38 \text { individuals }\end{array}$ & & \\
\hline $\begin{array}{l}\text { Reason for online } \\
\text { physiotherapy } \\
\text { consultation (possible } \\
\text { to select more than one) }\end{array}$ & $\begin{array}{l}\text { Continuation of } \\
\text { therapy } \\
83\end{array}$ & $\begin{array}{l}\text { Start therapy from } \\
\text { referral } \\
12\end{array}$ & $\begin{array}{l}\text { Impeded access to } \\
\text { physiotherapist } \\
19\end{array}$ & $\begin{array}{l}\text { Other (worrying symp- } \\
\text { toms, evaluation of } \\
\text { child's development) } \\
94\end{array}$ \\
\hline
\end{tabular}

had previously received in-clinic physiotherapy (113 people), the most frequently mentioned reason for video consultations was the wish to continue the rehabilitation they had started prior to the outbreak of the pandemic (83 people). 45 respondents had recently noticed worrying symptoms in their child and wanted consultation on these and online consultation was the only available form. 12 respondents admitted that they had been waiting for this opportunity even prior to the outbreak of the pandemic, because distance impedes their access to physiotherapists. Finally, 7 respondents had recently been referred to a physiotherapist for consultation, but the ongoing pandemic had made this in-clinic consultation impossible.

In the group of respondents (38 people) for whom the video consultation was the first contact with a physiotherapist, the vast majority said that they had recently discerned worrying symptoms in their child or that they wanted to make sure their child was developing properly, and that because of the pandemic, they could only do so online. Only 5 respondents admitted that they had recently received a referral for rehabilitation from a doctor and online consultation was the only possible solution due to the prevailing situation.

The question about the benefits of online consultations was an open question. The most commonly mentioned benefit was the travel time saved when seeing a physiotherapist. This convenience was particularly important for respondents with more than one child, as the illness of one of these children often made it impossible to travel to an in-person appointment.

The possibility of consulting a specialist with whom it would otherwise be impossible to meet because of the distance was repeatedly emphasised as a convenience. People from small towns and villages, as well as those living abroad, drew attention to the problem of a shortage of paediatric physiotherapists in their place of residence. Another important aspect for the respondents was the possibility of continuing the therapy.

Respondents noted the child's greater sense of security in an environment they knew. This translated into their being calm and cooperating more successfully. Many responses mentioned conveniences such as the ability to record the consultation and replay it and to send videos of the child's progress observed at home. Finally, respondents also appreciated the hygienic aspects of contactless consultation related to safety during the pandemic.

The next questions concerned the limitations of visiting a physiotherapist online. Fifty-four respondents (36\%) said that the lack of the physiotherapist's presence made it slightly difficult for them to do exercises with their child. Thirty-seven respondents (24\%) regarded that this difficulty as significant or extreme. 74 respondents (49\%) did not experience any technical difficulties or limitations during the consultation, while 12 respondents (8\%) admitted that the technical conditions significantly or extremely impeded the video consultation. The need for help from a third person during online consultation was noted by 87 respondents $(58 \%)$.

Increased confidence in dealing with the child correctly at home following the online consultation was reported by 117 respondents (77\%). When asked whether an online video consultation could replace in-person consultation, 61 respondents answered that this would sometimes be possible (figure 1). Forty respondents 


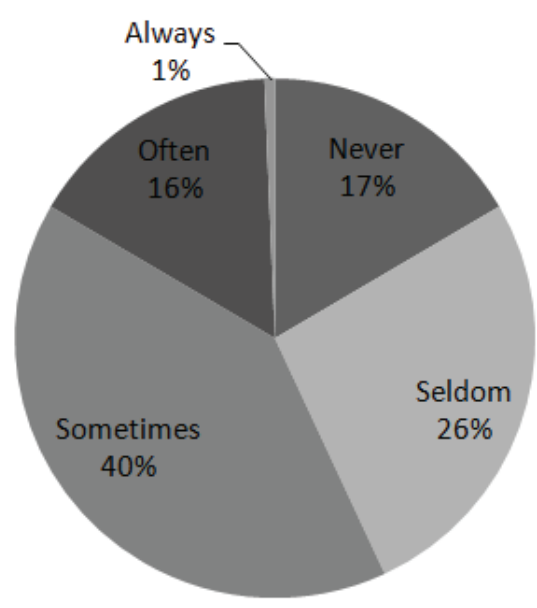

Fig. 1. Possibility and frequency of replacing in-clinic consultation with online consultation - percentage distribution

gave a negative answer. Twenty-five people stated that online consultation could never replace in-person consultation.

A total of 131 respondents indicated that they would be willing to go online again if access to face-to-face appointments was limited (figure 2). Even if in-person visit were possible, 47 parents would use the online consultation again.

In the final open question, respondents could share their opinions about the online consultation with a physiotherapist. According to the respondents, the most important factor influencing the quality of the visit was the level of preparation, both technical and substantive. Receiving the test results and videos of the child in motion prior to the consultation gave the physiotherapist more time to evaluate the patient.

Many parents reported difficulty in manoeuvring the camera when doing exercises with their child. A tripod proved helpful for this, as it freed up both the parent's hands. Access to a good-quality internet connection was an important factor. The respondents stressed that the lack of the physiotherapist's direct presence had a negative impact on the quality of their exercises with the child. They were unsure whether they had correctly

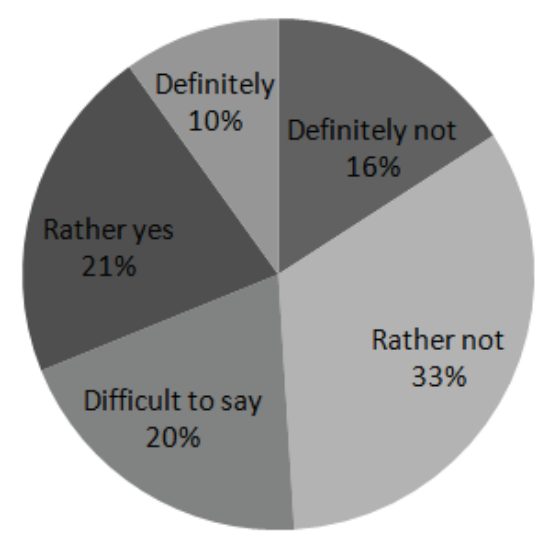

Fig. 2. Willingness to have online consultation again given the option of a face-to-face visit - percentage distribution

reproduced the movement shown by the therapist. The positive impression of the video consultation was influenced by openness, lack of haste and a good attitude on the part of the physiotherapist.

Based on the statistical analysis of the data, the authors elicited a number of relationships between the issues examined in each question. They investigated whether the previous use of in-clinic physiotherapy is related to the assessment of the appropriateness of using online consultation (table 2). The chi-square test did not reveal a significant relationship as its value $=0.97$ did not exceed the critical value $=5.99$. It was therefore concluded that the ability of parents to compare the two forms of consultation does not affect their evaluation of the legitimacy of the use of online consultation.

The authors checked whether the reason for previous consultations had an influence on the assessment of the appropriateness of using online consultations (table 3). It was only in the case of positional asymmetry that the chi-square test revealed a statistically significant association. It was noted that in all other cases, a significant majority believed that the online consultation was performed its role, whereas for children with asymmetry, the largest group was 'undecided'.

Tab. 2. Evaluation of the appropriateness of using online consultations, depending on whether respondents had previously used face-to-face consultations

\begin{tabular}{|c|c|c|c|c|c|}
\hline & \multicolumn{5}{|c|}{ Evaluation of the appropriateness of using online consultations } \\
\hline \multirow{4}{*}{$\begin{array}{l}\text { Previous use of online } \\
\text { physiotherapy consultation }\end{array}$} & $\mathrm{P}=0.05$ & $x^{2}=0.97$ & No & Difficult to say & Yes \\
\hline & $\mathrm{n}=2$ & $x_{a}^{2}=5.99$ & 23 & 48 & 80 \\
\hline & No & 38 & 4 & 12 & 22 \\
\hline & Yes & 113 & 19 & 36 & 58 \\
\hline
\end{tabular}


Tab. 3. Assessment of the appropriateness of using online consultation, depending on the child's problem

\begin{tabular}{lcc}
\hline \multicolumn{2}{c}{ Assessment of the appropriateness of using online consultation } \\
\hline Reason for prior consultation with physiotherapist & $x^{2}$ & $x_{a}^{2}$ for $\mathrm{n}=2$ \\
To learn how to take care correctly & 2.71 & 5.99 \\
Assessment of the child's development & 0.74 & 5.99 \\
Asymmetry & 9.44 & 5.99 \\
Muscle tension disorder & 0.73 & 5.99 \\
Diagnosed syndrome or medical condition & 3.16 & 5.99 \\
Delayed motor development & 0.77 & 5.99 \\
\hline
\end{tabular}

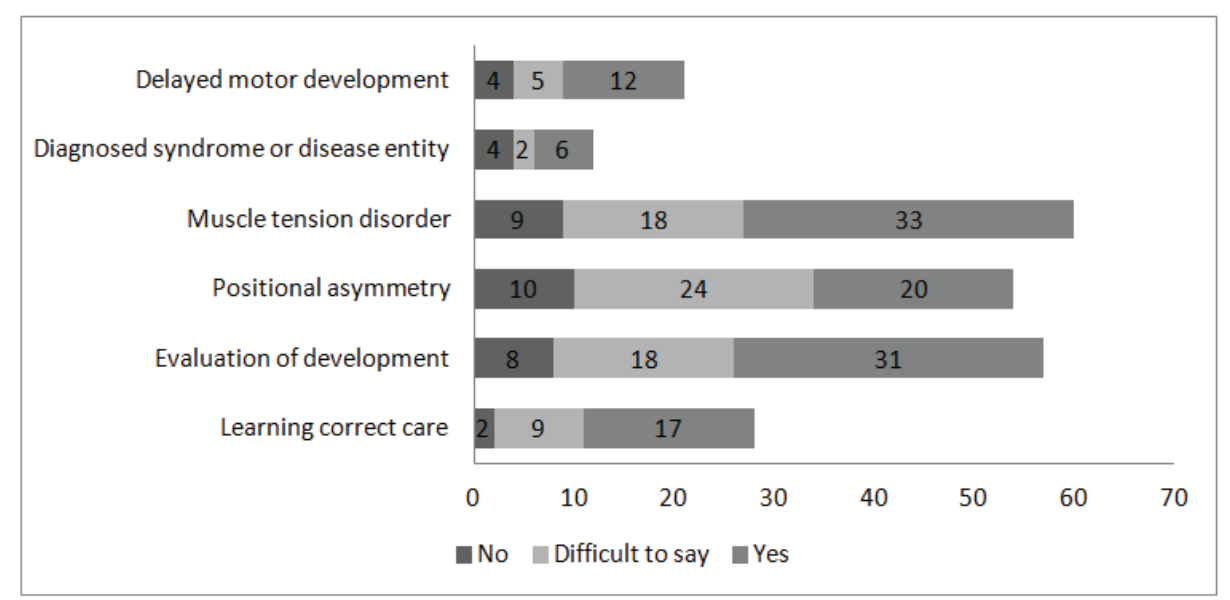

Fig. 3. Relevance of using online consultation, depending on the reason for previous consultation (child's problem)

Those parents whose reason for previous visits to a physiotherapist was to learn how to take care correctly gave the highest rating for the appropriateness of using online consultations (figure 3 ). However, this relationship was not statistically significant.

It was noted that the greatest statistically significant relationship with the evaluation of the appropriateness of the use of online consultations was whether respondents felt more confident after this form of visit as regards the correct action to take at home (table 4). The chi-square test value for these questions is $=34.14$ with a critical value $=9.49$.
It transpired that the second statistically significant factor influencing the assessment of the validity of using online consultation is the ability to repeat the exercises shown by the therapist. Increased confidence in doing the correct exercises with the child at home is strongly related to the ability to repeat the exercises shown by the therapist during the video consultation (table 5). The test value for these variables is $=59.13$ against a critical value of 9.49 .

The survey found that the factor that statistically significantly affects the assessment of the possibility of replacing in-person consultations with online

Tab. 4. Evaluation of the validity of the use of online consultation according to the increase in confidence in the correct action to take with the child at home after online consultation

\begin{tabular}{lccccc}
\hline & \multicolumn{5}{c}{ Assessment of the appropriateness of using online consultation } \\
\hline & $\mathrm{p}=0.05$ & $x^{2}=34.14$ & No & Difficult to say & Yes \\
Increased sense & $\mathrm{n}=4$ & $x_{a}^{2}=9.49$ & 23 & 48 & 80 \\
of confidence & No & 15 & 9 & 5 & 4 \\
& Difficult to say & 19 & 9 & 36 & 6 \\
& Yes & 117 & & & 72 \\
\hline
\end{tabular}


Tab. 5. Increased confidence in the correct management of the child at home depending on the ability to repeat the exercises shown during the online consultation

\begin{tabular}{lccccc}
\hline & \multicolumn{5}{c}{ Increased sense of confidence } \\
\hline & $\mathrm{p}=0.05$ & $x^{2}=59.13$ & No & Difficult to say & Yes \\
Ability to replicate & $\mathrm{n}=4$ & $x_{a}^{2}=9.49$ & 15 & 19 & 117 \\
exercises & No & 9 & 6 & 0 & 3 \\
& Difficult to say & 19 & 4 & 8 & 7 \\
& Yes & 123 & 5 & 11 & 107 \\
\hline
\end{tabular}

consultations is the degree of difficulty the respondent experienced because of the technological limitations of their equipment.

\section{Discussion}

The situation stemming from the SARS-CoV-2 coronavirus and the resulting changes in the organisation of health care facilities have had a negative effect on the availability of rehabilitation services in most European countries. The solution to this problem proved to be telerehabilitation. This allowed rehabilitation needs to be met when the physiotherapist and the patient are in two different places [6-9].

Infants are a group of patients particularly at risk of significant and irreversible worsening of their disorders as a result of rehabilitation interventions not being provided or being interrupted. Implementing early intervention for children at risk of disability is important because during this period in their life they show particular readiness to learn basic motor, social and emotional skills [2]. The aim of this study was to evaluate how parents perceive the use of an online format in paediatric physiotherapy consultations. The research questions concerned the influence of online consultations on parents' increased sense of competence in dealing with their child correctly, the possibility of replacing the stationary consultation with an online version, and the benefits and limitations of conducting this form of support.

The issue analysed was the country and place of residence of the respondents. $10 \%$ of members of this group were living abroad. Most declared that they wished to use the emerging possibility of online consultation because they had difficult access (or lack of it) to in-clinic physiotherapy. Respondents living in rural areas or small towns also repeatedly cited a shortage of paediatric physiotherapists. The emergence of online consultation has provided an opportunity to seek advice from a specialist that parents could not visit in person due to distance, for example. This undoubted recommendation of telerehabilitation is also mentioned by Maggio et al. in their study [6]. They believe that in addition to the need to use it in all countries where the pandemic has forced the closure of rehabilitation facilities, "this innovative service can be an alternative for patients living in rural areas, mountainous areas and islands and reduce the need for elderly patients with chronic polyposis to travel" [6].

More than $30 \%$ of respondents declared a willingness to use online consultations in the future, even if there was already an option for in-person services. Many emphasised that a major advantage was saving double the time. The waiting time for the consultation was reduced, which enabled parents to find out more quickly about the symptoms that concerned them and to implement possible therapy, as well as to save time spent travelling and avoid the inconvenience of travelling with a small child.

The dominant group (85\%) participating in the study were parents of children under 1 year of age. The great interest in consultations among the parents of the youngest children may indicate their heightened awareness of the importance that an early physiotherapy assessment might have for the future development of the child and of the possible need for intervention. 29\% of the respondents reported that the physiotherapist providing the online consultation was not the one who had previously treated their child, and $45 \%$ of these said they used the video consultation because it provided an opportunity to contact a particular therapist with whom they would otherwise not have had the chance to meet face-to-face. This result shows that there is a need among the parents of paediatric patients to have contact with selected specialists. As highlighted by many researchers, online consultations allow spatial, time and financial barriers to be overcome [10-13].

Eighty percent of respondents confirmed that they experienced no major problems resulting from the technological capabilities of their equipment. In their study, Libertus and Violi [14] concluded that access to the internet and digital equipment is an important factor that may limit parents' participation in this type of 
consultation. The analysis showed that a positive assessment of the appropriateness of using online consultations correlated most strongly with an increase in confidence in the correct way to deal with the child at home. This confidence increased in $77 \%$ of respondents. The parents' ability to remember the exercises shown by the physiotherapist during the online consultation had a strong impact on this confidence. This was the strongest relationship among all the pairs of variables studied. In $87 \%$ of those who reported being able to repeat the exercises, the sense of confidence increased and along with it, the sense of fear and helplessness generated by the pandemic situation decreased.

On the other hand, with the ability to repeat the exercises, the strongest statistically significant relationship was revealed by the question about the degree of difficulty in performing the exercises due to the absence of the physiotherapist's direct presence. However, many respondents stressed that they lacked confidence in their ability to replicate the movement shown by the therapist correctly. The carers were concerned that without a palpation examination the specialist would not be able to see all the abnormalities in the child.

As a result of the search for a variable that was related to the extent of the aforementioned difficulties experienced by the parents, it was found that these depended in a statistically significant way on whether the respondents had previously had an opportunity to make use of in-clinic physiotherapy. It transpired that parents who had not previously had such physiotherapy experienced much less difficulty. $74 \%$ of the respondents in this group declared that they felt no or little discomfort from the physical absence of a therapist. However, in the group who had previously received in-clinic physiotherapy, only $42 \%$ of the respondents experienced no difficulties.

The largest number $(40 \%)$ of respondents felt that online consultations could "sometimes" replace in-clinic visits. On the other hand, $26 \%$ of respondents (the second most popular answer) suggested that a traditional consultation could "rarely" be replaced by an online visit. This implies that in the opinion of parents, in-clinic consultations can be replaced by online consultations only in certain emergency situations (inability to travel, illness) or when the video consultation is a complement to traditional consultations in order to check the correctness of exercises performed and possible correction and the need to modify them in response to the changing needs of the child. Therefore, it can be concluded that the two forms of consultation (in-clinic and online) can complement each other, as video consultation allows for more frequent contact with the physiotherapist. The possibility of more frequent but shorter meetings, without exposing the child to time-consuming travel [15], infections and infestations [16] will facilitate ongoing monitoring of the course of therapy.

In recent years, telerehabilitation has developed rapidly, but it has mostly been used as a supplement to basic therapy or as an extension of it. The outbreak of the COVID-19 pandemic forced it to develop unexpectedly and dynamically. As telerehabilitation entered new areas, studies began to appear that evaluated the effectiveness of its new applications [6-9,17-19]. However, few reports currently exist on the validity of using video consultations in paediatric physiotherapy. Sgandurra et al. [20] evaluated the effect of early home intervention with the telerehabilitation tool "System CareToy" on the early motor and visual development of preterm infants. The findings of this study show that it is possible to conduct effective early intervention in a home setting.

In line with the Polish Model of Rehabilitation, reated by Dega, Weiss and Hulk, the effectiveness of the rehabilitation process is influenced by such features as earliness, continuity, universality and comprehensiveness [21]. The situation caused by the pandemic temporarily prevented these from being implemented. The research described in this paper shows that online consultations are largely able to restore the possibility of carrying out rehabilitation in a crisis situation.

One limitation of the study is its relatively small sample of respondents, which is due to the diagnostic survey having been conducted in the first weeks of the pandemic in Poland, i.e. when online infant consultations were just beginning to be used. Due to the virtual nature of the questionnaire, both the surveyed group (parents) and the physiotherapists conducting online consultations are people fluent in the use of Internet tools, which affects the low socio-demographic diversity of both groups.

It would be advisable to carry out research into the effectiveness of using online consultations for infants and young children and to investigate the validity of providing paediatric therapy using modern IT tools. It would be interesting to analyse the effectiveness of online physiotherapy depending on the medical condition, the functional level, the purpose of therapy or the patient's environmental constraints.

\section{Conclusions}

1. Online physiotherapy consultation increases parents' confidence in how to deal with their child properly.

2. The advantages of online physiotherapy consultations are the flexible conditions for physiotherapy treatment and the great availability of the service, especially during the pandemic. 
3. In the opinion of parents of infants, the greatest limitation of this form of support is the lack of direct contact with the physiotherapist.

4. Online consultation cannot replace face-to-face consultation, but can supplement it effectively.

\section{Funding}

This research received no external funding.

\section{Conflicts of interest}

The authors declare no conflict of interest.

\section{References}

1. Kaczmarek T. Wczesna interwencja. In: Bożkowa K, red. Encyklopedia zdrowia dziecka. Warszawa: Emu; 1994. p. 17.

2. Cecchi F, Sgandurra G, Mihelj M, Mici L, Zhang J, Munihet M, et al. Home-based intervention for infants at risk for neurodevelopmental disorders. Ieee robotics \& automation magazine. 2016; 23(4): 2-10.

3. Gluźniewicz J. Wczesne wspomaganie rozwoju dziecka niepełnosprawnego - główne założenia i problemy. In: Skibska J, red. Wspieranie rozwoju małego dziecka. Kraków: LIBRON - Filip Lohner; 2014. p. 51-62.

4. Cytowska B, Winczur B, editors. Wczesna interwencja i wspomaganie rozwoju małego dziecka. Kraków: Oficyna wydawnicza „Impuls”; 2011.

5. Sidor-Piekarska B. Wczesna interwencja jako wspomaganie rozwoju dziecka z trudnościami rozwojowymi i udzielanie wsparcia jego rodzicom. Roczniki Pedagogiczne. 2010; 2(38).

6. Maggio MG, De Luca R., Manuli A, Salvatore Calabrò RS. The five ' $\mathrm{W}$ ' of cognitive telerehabilitation in the Covid-19 era. Expert Rev Med Devices. 2020; 17(6): 473-5.

7. Negrini S, Kiekens C, Bernetti A, Capecci M,Ceravolo $\mathrm{MG}$, Lavezzi $\mathrm{S}$ et al. Telemedicine from research to practice during the pandemic. "Instant paper from the field" on rehabilitation answers to the Covid-19 emergency. Eur J Phys Rehabil Med. 2020; 56(3): 327-30.

8. Negrini S, Ferriero G, Kiekns C, Boldrini P. Facing in Real time the challenges of the Covid-19 epidemic for rehabilitation. Eur J Phys Rehabil Med. 2020; 56(3): 313-5.
9. Bashshur R, Doarn CR, Frenk JM, Kvedar JC, Woolliscroft JO. Telemedicine and the COVID-19 Pandemic, Lessons for the Future. Telemedicine and e-health. 2020; 571-3.

10. Burke Jr BL, Hall RW, section on telehealth care. Telemedicine: Pediatric Applications. Pediatrics. 2015; 136(1): e293-e308.

11. Olson CA, McSwain SD, Curfman AL, Chuo J. The Current Pediatric Telehealth Landscape. Pediatrics. 2018; 141(3): e20172334.

12. Utidjian L, Abramson E. Pediatric Telehealth: Opportunities and Challenges. Pediatr Clin North Am. 2016; 63(2): 367-78.

13. Boonzaaijer M, van Wesel F, Nuysink J, Volman MJM, Jongmans MJ. A home-video method to assess infant gross motor development: parent perspectives on feasibility. BMC Pediatr. 2019; 19: 392.

14. A. Violi D, Libertus K. Sit to Talk: Relation between Motor Skills and Language Development in Infancy. Front. Psychol. 2016; 7: 475.

15. Paruthi S. Telemedicine in Pediatric Sleep. Sleep Med Clin. 2020; 15(3): e1-e7.

16. Sasangohar F, Davis E, Kash BA, Shah SR. Remote Patient Monitoring and Telemedicine in Neonatal and Pediatric Settings: Scoping Literature Review. J Med Internet Res. 2018; 20(12): e295.

17. Fiani B, Siddiqi I, Lee SC, Dhillon L. Telerehabilitation: Development, Application, and Need for Increased Usage in the COVID-19 Era for Patients with Spinal Pathology. Cureus. 2020; 12(9): e10563.

18. Tenforde AS, Borgstrom H, Polich G, Steere H, Davis IS, Cotton K et al. Outpatient Physical, Occupational, and Speech Therapy Synchronous Telemedicine: A Survey Study of Patient Satisfaction with Virtual Visits During the COVID-19 Pandemic. Am J Phys Med Rehabil. 2020; 99(11): 977-81.

19. Turolla A, Rossettini G, Viceconti A, Palese A, Geri T. Musculoskeletal Physical Therapy During the COVID-19 Pandemic: Is Telerehabilitation the Answer? Phys Ther. 2020 12; 100(8): 1260-4.

20. Sgandurra G, Lorentzen J, Inguaggiato E, Bartalena L, Beani E, Cecchi $\mathrm{F}$ et al. A randomized clinical trial in preterm infants on the effects of a home-based early intervention with the 'CareToy System'. PLoS One. 2017; 12(3): e0173521.

21. Lubecki M. Polski model rehabilitacji medycznej zaakceptowany i zalecany przez WHO. Hyg Pub Health. 2011; 46(4): 506-15. 